\title{
Reduction of Opioid Con- sumption after Major Spinal Surgery without Neurological Impairment by Block of Rami Dorsales
}

\section{Axel F Unterrainer ${ }^{1 *}$, Martin Kurz' ${ }^{1}$, Monika Unterrainer ${ }^{2}$, Wolf- gang Hitzl ${ }^{3}$, Rahman Al Schameri ${ }^{4}$ and Peter A Winkler ${ }^{4}$}

${ }^{1}$ Department of Neuroanesthesiology, Paracelsus Medical University Salzburg, Austria

${ }^{2}$ Department of German Philology, Paris Lodron University of Salzburg, Austria

${ }^{3}$ Department of Biostatistics, Paracelsus Medical University of Salzburg, Austria

${ }^{4}$ Department of Neurosurgery, Paracelsus Medical University of Salzburg, Austria

\begin{abstract}
Background: Epidural anesthesia reduces the demand on opioids after lumbar major spinal surgery. But it does not allow early postoperative assessment of motor function. Aims of the study were to elucidate a comparable effect of blocking rami dorsales on analgesic quality as well as an influence of this technique on motor function.

Methods: Twenty two patients scheduled for lumbar interbody fusion were enrolled and divided randomly in 2 groups. Group A received a block of rami dorsales bilateral of fused vertebrae with bupivacaine $0.5 \% 2 \mathrm{ml} 20$ minutes before expected end of operation and a Patient Controlled Analgesia (PCA) pump. Group B received PCA pump only. The demand of piritramide to achieve a visual analogue pain score of less than 3 was given either by nurse or PCA pump when patients were co-operative. Setting of the PCA pump, co-analgesic and rescue medication was the same for all patients. Total sum of piritramide and rescue medication given within 24 hours postoperatively was recorded. Modified Bromage scale was assessed in all patients 1 hour after operation.
\end{abstract}

Results:Thegroupswerecomparedbypairs. Thepostoperativeamount of piritramide given by nurse and by PCA pump differed significantly

*Corresponding author: Axel F Unterrainer, Department of Neuroanesthesiology, Paracelsus Medical University Salzburg, Austria, Tel: +43 5725556410; E-mail: A.F.Unterrainer@salk.at

Citation: Unterrainer AF, Kurz M, Unterrainer M, Hitzl W, Schameri RA, et al (2017) Reduction of Opioid Consumption after Major Spinal Surgery without Neurological Impairment by Block of Rami Dorsales. J Anesth Clin Care 4: 022.

Received: April 27, 2017; Accepted: July 18, 2017; Published: July 31, 2017
$(\mathrm{P}<0.05$ ). The amount of piritramide given during stay in recovery room did not differ between the two groups. Modified Bromage scale was 0 in all patients.

Conclusion: Block of rami dorsales reduces in a simple way the postoperative demand on piritramide in lumbar major spinal surgery without any impairment of lower extremity's motor function.

Keywords: Analgesics; Nerve block; Opioid; Pain postoperative

\section{Background}

The opioid sparing effect of epidural analgesia in pain treatment after lumbar major spinal surgery has yet to be proven [1-3].

But epidural analgesia does not allow early detection of neurological impairment caused either by hematoma or by screw malposition [4]. Lumbar rami dorsales supply sensorialy facet joints, spinal ligaments, spinal muscles, hypodermis, and the skin [5]. The radiological guided transcutaneous approach to block off rami dorsales' medial ramus, which supplies the sensory in nervation of the lumbar facet joints, by local anesthetics is widely used to treat chronic lower back pain [6,7]. The efficacy in pain relief of blocking the lateral rami too, which supply the sensory innervation of muscles, hypodermis and dermis of the back has never been studied [5].

The aim of this study was to investigate the influence of rami dorsales' block on opioid consumption within 24 hours postoperative as well as on motor function of lower extremity immediately after surgery. A Visual Analogue pain Score (VAS) of 3 or less was considered as acceptable in treatment of postoperative pain.

\section{Methods}

After registration on EudraCT database, number, 2014-005104-21, approval of the local Ethic Committee, and written informed consent twenty two opioid naive patients of both sex scheduled for open fusion of two lumbar vertebrae were enrolled. This prospective, randomized, sample sized planned, double blinded and controlled clinical trial was designed for testing the hypothesis that the administration of bupivacaine to the common branches of rami dorsales influences the postoperative demand on piritramide given by nurses, who were blinded to patient's group, and by Patient Controlled (PCA) infusion pump. Furthermore a possible effect on motor function of lower extremity caused by accidental flow of bupivacaine to ventral root was investigated.

Patients were randomly allocated to two groups based on computer generated random numbers. Group A - PCA plus injection of $2 \mathrm{ml}$ bupivacaine $0.5 \%$ bilaterally into the tissue of the musculi intertransversarii laterals lumborum above the upper edge of process us transverse of the two fused lumbar vertebrae with intention to block medial and lateral branch of rami dorsales (Figure 1). Totally bupivacaine 40 $\mathrm{mg}$ divided in four injections were administered. With intention to minimize the risk of nerve injury a cushing needle was used for injection. This procedure was performed by the surgeon 20 minutes before expected skin closure. Patients in Group B received bolus doses of piritramide using PCA pump only. 


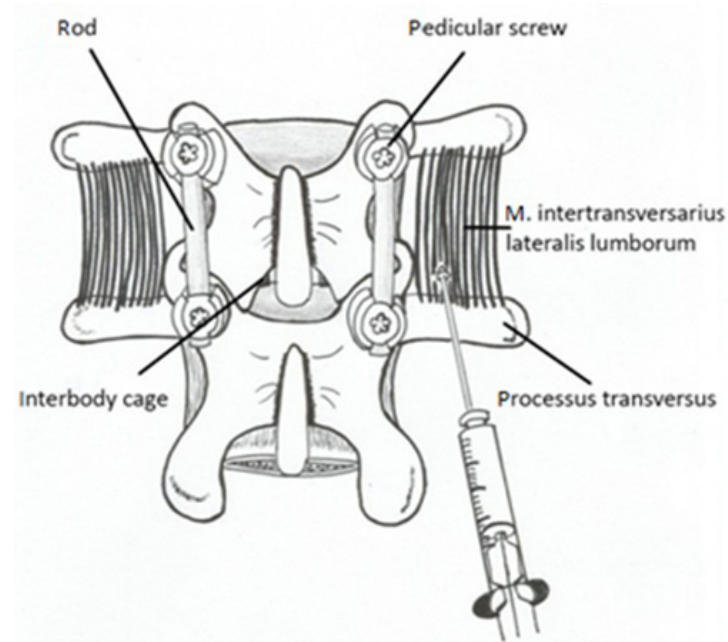

Figure 1: Drawing of the operating field.

In both groups anesthesia was started with propofol and maintained with sevoflurane. Fentanyl was given prior to expected anesthesiological and surgical stimuli. Rocuronium was used to facilitate intubation. Piritramide $0.08 \mathrm{mgkg}^{-1}$ and diclofenac $75 \mathrm{mg}$ were given Intravenously (IV) 20 minutes before expected skin closure. Diclofenac $75 \mathrm{mg}$ IV was infused to all patients 12 hours postoperatively.

Standard $10 \mathrm{~cm}$ VAS (from 0, no pain to 10, worst imaginable pain) was assessed after awakening, before leaving the recovery room, 24 hours postoperatively and optionally before administration of rescue medication. With intention to avoid respiratory depression single injections of piritramide were given titrated IV by medical staff whenever patient expressed pain. Criterion for discharge from recovery room in terms of pain management was a VAS of 3 or less.

Time from operation's end to first request on analgesics was recorded.

The PCA pump was explained to all patients the day before surgery. It was connected before patients were dismissed on ordinary ward. According to a previous study the bolus dose was piritramide $2 \mathrm{mg}$, the lock out time was 20 minutes and the maximum dose given within 4 hours was piritramide $15 \mathrm{mg}$ [8].

Paracetamol 1g IV was prescribed for both groups if adjusted PCA therapy failed to achieve VAS less than 3. If paracetamol $1 \mathrm{~g}$ IV also would have failed, metamizol $\mathrm{lg}$ IV was the next option.

Motor function of lower extremities was assessed by modified Bromage scale one hour postoperatively [9].

The sum of administered piritramide and paracetamol was evaluated 24 hours after operation's end.

\section{Statistical methods}

Sample size: an a priori sample size computation was done to estimate the sample size to achieve a power of $90 \%$ to detect a significant difference of $0.073 \mathrm{mgkg}^{-1}$ piritramide between both groups. The standard deviations were estimated based on results of a former study (Table 1, Figure 2) [8]. The amounts of piritramide and paracetamol were calculated in milligram respectively in gram because postoperative administration of these drugs was not based on body weight (Table 2, Figure 3). The sample size computation was based on a one-sided unpaired Student t-test with unequal variances and ends up with a sample size of $n=13$ in group A and $n=9$ in group $B$.

\section{Discussion}

The study showed that patients who underwent dorsal rami nerve block by a local anesthetic in pain treatment after major spinal surgery used fewer opioids in the 24 hours after surgery compared to patients who received typical anesthesia.

Our results go with Bademci's findings concerning the postoperative opioid sparing effect of intra-operative infiltration of bupivacaine to facet joints and to overlying tissues in lumbar disc surgery [10]. Furthermore our technique of blocking rami dorsales including ramus lateralis provides sufficient analgesia for muscles, hypodermis and dermis without an additional infiltration of bupivacaine into these tissues. This might avoid potential toxic side effects caused by overdosing bupivacaine [11].

The absence of difference in time between extubation and first request on analgesic and large standard deviation in group A might be explained by delayed onset of bupivacaine [12]. A possible impairment of lower extremities motor function caused by rami dorsales block could be excluded. This scenario might have been feasible if local anesthetic flowed accidentally of to anterior root. Unrestricted motor function of lower extremity after application of our method was proven by this study.

Compared to epidural administration of local anesthetics, either by single shot or by continuous infusion via catheter, our technique allows an immediate neurological assessment after awakening from anesthesia.

The absence of a study group treated by saline only was one weakness of this study. Patient's informed consent to this type of treatment was not expectable. The others were the small number of patients and that VAS score was not assessed before surgery.

It could be the case that patients in Group B had more severe pain before and after surgery and the block of rami dorsales had no effect. Dose finding concerning lower concentration and lower volume of bupivacaine solution with the same analgesic efficacy and analysis of plasma levels shall be the topic of further studies.

\section{Conclusion}

Dorsal rami nerve block in major lumbar spinal surgery reduces postoperative piritramide demand without any impairment of lower extremity's motor function in a simple way.

\section{Abbreviations}

PCA: Patient Controlled Analgesia

VAS: Visual Analogue Scale

ASA: American Society of Anesthesiologists

SD: Standard Deviation

\section{Acknowledgments}

We wish to thank the personal at the Department of Neuroanesthesiology of Christian Doppler Klinik Salzburg Austria for the practical help. Special thanks are given to Trixie Baker, B.Sc., for her precious help in language consultancy.

\section{Funding}

The project was funded by the department and by private sponsoring of the corresponding author. 
Citation: Unterrainer AF, Kurz M, Unterrainer M, Hitzl W, Schameri RA, et al. (2017) Reduction of Opioid Consumption after Major Spinal Surgery without Neurological Impairment by Block of Rami Dorsales. J Anesth Clin Care 4: 022.

- Page 3 of $4 \cdot$

\begin{tabular}{|c|c|c|c|c|c|}
\hline \multirow[t]{2}{*}{ Variable } & \multicolumn{2}{|c|}{ Group A (n=13) } & \multicolumn{3}{|c|}{ Group $B(n=9)$} \\
\hline & Mean & Standard deviation & Mean & Standard deviation & $p$-value \\
\hline Age (years) & 59.5 & 12.6 & 62.0 & 16.0 & 0.69 \\
\hline Height $(m)$ & 1.68 & 0.04 & 1.71 & 0.09 & 0.23 \\
\hline Weight $(\mathrm{kg})$ & 74.2 & 13.8 & 87.2 & 18.6 & 0.07 \\
\hline VAS after extubation & 0.77 & 1.54 & 1.56 & 2.05 & 0.10 \\
\hline $\begin{array}{l}\text { VAS before discharging } \\
\text { from recovery room }\end{array}$ & 0.92 & 1.19 & 1.44 & 1.01 & 0.30 \\
\hline $\begin{array}{l}\text { VAS } 24 \text { hours after } \\
\text { operation }\end{array}$ & 0.46 & 0.78 & 0.89 & 0.60 & 0.18 \\
\hline Blood loss (ml) & 415.4 & 89.9 & 664.4 & 519.6 & 0.10 \\
\hline length of OP $(\mathrm{min})$ & 140.3 & 25.3 & 192.9 & 81.2 & 0.09 \\
\hline \multicolumn{6}{|l|}{ Men } \\
\hline Age (years) & 64.0 & 8.9 & 58.9 & 16.6 & 0.51 \\
\hline Height $(m)$ & 1.75 & 0.05 & 1.75 & 0.06 & 0.83 \\
\hline Weight (kg) & 80.5 & 16.2 & 94.3 & 11.9 & 0.10 \\
\hline VAS after extubation & 1.00 & 1.67 & 1.71 & 2.36 & 0.55 \\
\hline $\begin{array}{l}\text { VAS before discharging } \\
\text { from recovery room }\end{array}$ & 0.83 & 1.33 & 1.43 & 0.79 & 0.34 \\
\hline $\begin{array}{l}\text { VAS } 24 \text { hours after } \\
\text { operation }\end{array}$ & 0.83 & 0.98 & 0.86 & 0.69 & 0.96 \\
\hline Blood loss (ml) & 400.0 & 109.5 & 640.0 & 579.7 & 0.34 \\
\hline length of OP (min) & 138.8 & 24.9 & 172.6 & 61.2 & 0.23 \\
\hline \multicolumn{6}{|l|}{ Women } \\
\hline Age (years) & 55.7 & 14.6 & 73.0 & 8.5 & 0.12 \\
\hline Height $(m)$ & 1.63 & 0.07 & 1.58 & 0.08 & 0.38 \\
\hline Weight (kg) & 68.9 & 9.4 & 62.5 & 19.1 & 0.72 \\
\hline VAS after extubation & 0.57 & 1.51 & 1.00 & 1.41 & 0.75 \\
\hline $\begin{array}{l}\text { VAS before discharging } \\
\text { from recovery room }\end{array}$ & 1.00 & 1.15 & 1.50 & 2.12 & 0.80 \\
\hline $\begin{array}{l}\text { VAS } 24 \text { hours after } \\
\text { operation }\end{array}$ & 0.14 & 0.38 & 1.00 & 0.00 & 0.018 \\
\hline Blood loss (ml) & 428.6 & 75.6 & 750.0 & 353.6 & 0.42 \\
\hline length of OP $(\mathrm{min})$ & 141.6 & 27.6 & 264.0 & 131.5 & 0.41 \\
\hline
\end{tabular}

Table 1: Demographic data, VAS scores, blood loss, length of operation.

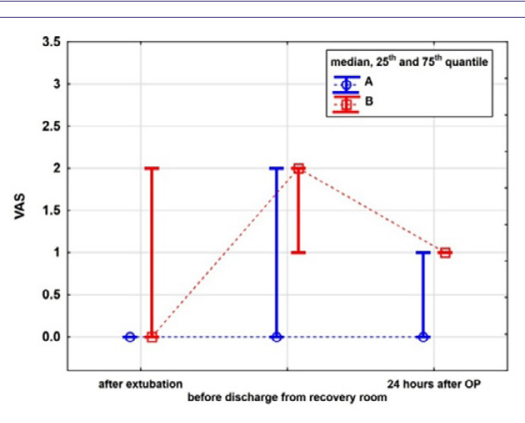

Figure 2: VAS scores.

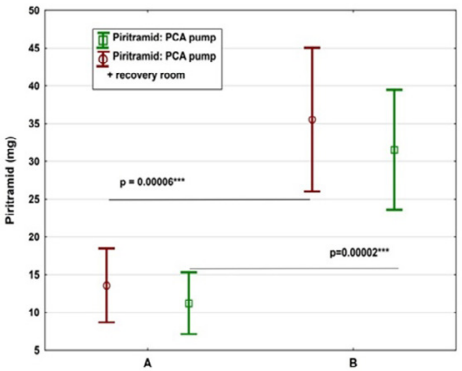

Figure 3: Amount of given piritramide.

\begin{tabular}{|c|c|c|c|c|c|c|c|c|c|c|}
\hline Variable & $\begin{array}{c}\text { Mean } \\
\mathbf{A}\end{array}$ & $\begin{array}{c}\text { Mean } \\
\mathbf{B}\end{array}$ & $\mathbf{p}$ & $\begin{array}{c}\text { Valid } \\
\mathbf{N}\end{array}$ & $\begin{array}{c}\text { Valid } \\
\mathbf{N}\end{array}$ & $\begin{array}{c}\text { Standard } \\
\text { deviation }\end{array}$ & $\begin{array}{c}\text { Standard } \\
\text { deviation }\end{array}$ & $\begin{array}{c}\text { Mean } \\
\mathbf{1}\end{array}$ & Confidence & Confidence \\
\hline $\begin{array}{c}\text { Amount of piritramide given via PCA pump postop- } \\
\text { eratively mg }\end{array}$ & 11.23 & 31.56 & 0.000018 & 13.00 & 9.00 & 6.76 & 10.33 & -20.32 & -28.82 & -11.83 \\
\hline Amount of piritramide given in recovery room $\mathbf{m g}$ & 2.35 & 4.00 & 0.298365 & 13.00 & 9.00 & 3.31 & 3.93 & -1.65 & -5.06 & 1.75 \\
\hline Sum piritramid mg & 13.58 & 35.56 & 0.000060 & 13.00 & 9.00 & 8.08 & 12.38 & -21.98 & -32.15 & -11.81 \\
\hline
\end{tabular}

Table 2: Amount of given piritramide. 


\section{Availability of Data and Materials}

Data are not publicly available. Data are available from the corresponding authors on reasonable request.

\section{Authors Contributions}

AFU contributed to the conception and design of the study, acquisition, analysis, and interpretation of data, and drafted the manuscript. MK and RA recruited the patients and performed data acquisition. MU carried out the drawings. WH performed the statistical planning and statistical analysis. PAW contributed to the anatomical considerations and to proofreading the manuscript. All authors gave final approval of the version to be published and agreed to be account for all aspects of the work.

\section{Competing interests}

The authors declare no conflict of interest.

\section{Ethics Approval and Consent to Participate}

The study was approved by the ethic committee of the federal state Salzburg, Austria, (no. 415-E/1516/20-2015). All subjects provided written informed consent and were free to withdraw from the study at any time of the investigation.

\section{References}

1. Gottschalk A, Freitag M, Tank S, Burmeister MA, Kreil S, et al. (2004) Quality of postoperative pain using an intraoperatively placed epidural catheter after major lumbar spinal surgery. Anesthesiology 101: 175-180.

2. Hodgson PS, Liu SS (2001) A comparison of ropivacaine with fentanyl to bupivacaine with fentanyl for postoperative patient-controlled epidural analgesia. Anesth Analg 92: 1024-1028.
3. Unterrainer AF, Al-Schameri AR, Piotrowski WP, Krombholz-Reindl MA, Schmid AL, et al. (2008) Opioid sparing effect of epidural levobupivacaine on postoperative pain treatment in major spinal surgery. Middle East $\mathrm{J}$ Anaesthesiol 19: 781-788.

4. Kluba T, Hofmann F, Bredanger S, Blumenstock G, Niemeyer T (2010) Efficacy of post-operative analgesia after posterior lumbar instrumented fusion for degenerative disc disease: a prospective randomized comparison of epidural catheter and intravenous administration of analgesics. Orthop Rev (Pavia) 2: 9.

5. Drake R, Vogl AW, Mitchell AWM (2014) Gray's Anatomy for Students E-Book (3edn). Elsevier Health Sciences, Amsterdam, Netherlands.

6. Misaggi B, Gallazzi M, Colombo M, Ferraro M (2009) Articular facets syndrome: diagnostic grading and treatment options. Eur Spine J 18: 49-51.

7. Schleifer J, Fenzl G, Wolf A, Diehl K (1994) Treatment of lumbar facet joint syndrome by CT-guided intraarticular infiltration of fact joints. Radiologe 34 : 666-670.

8. Unterrainer AF, Friedrich C, Krenn MH, Piotrowski WP, Golaszewski SM, et al. (2010) Postoperative and preincisional electrical nerve stimulation TENS reduce postoperative opioid requirement after major spinal surgery. J Neurosurg Anesthesiol 22: 1-5.

9. Kulkarni AP, Divatia JV, Patil VP, Gehdoo RP (2013) Objective Anaesthesia Review: A Comprehensive Textbook for the Examinees. Jaypee Brothers Medical Publishers (P) Ltd, Hyderabad, Telangana.

10. Bademci G, Basar H, Sahin S, Ozcakir S, Anbarci H, et al. (2008) Can facet joint infiltrative analgesia reduce postoperative pain in degenerative lumbar disc surgery? Neurocirugia (Astur) 19: 45-49.

11. Heavner JE (2007) Local anesthetics. Curr Opin Anaesthesiol 20: 336-342.

12. Miller RD, Eriksson LI, Fleisher LA, Wiener-Kronish JP, Cohen NH, et al. (2015) Miller's Anesthesia (8thedn). Elsevier Health Sciences, Ontario, Canada. 